\title{
Experimental Study on Behaviors of Adaptive-slit Shear Walls
}

\author{
Zhijuan Sun ${ }^{1}$, Jiliang $\mathrm{Liu}^{1}$ and Mingjin $\mathrm{Chu}^{2, *}$ \\ ${ }^{1}$ School of Architecture, Yantai University, Yantai ,264005,China \\ ${ }^{2}$ School of Civil Engineering, Yantai University, Yantai ,264005,China
}

\begin{abstract}
In order to meet the needs of performance-based seismic design, a new type of adaptive-slit shear wall that is easy to construct and behaves well under cyclic loading is introduced to improve the seismic performance of conventional shear wall structures. The seismic damage of an adaptive-slit shear wall develops gradually and it transforms from integral wall into slit wall. The mechanical characteristics of adaptive-slit shear walls suggest that such walls are adaptive to various seismic requirements under earthquakes of different intensities. Compared with conventional shear walls, the new wall is highly ductile and is advantageous in controlling the seismic damage process.
\end{abstract}

Keywords: Reinforced concrete, shear walls, slit shear walls, mechanical properties.

\section{INTRODUCTION}

China is an earthquake-prone country and earthquakes of high intensity have been frequently recorded across the country. One of the most recent severe earthquakes, Wenchuan earthquake, which occurred on May 12, 2008, caused huge casualties and property losses. Collapse of buildings structures is the main reason responsible for the casualties and property losses during the earthquake disaster. Therefore, it is important to improve the performance and anti-collapse ability of building structures to reduce the loss induced by earthquakes in the regions of high seismic hazard [1].

Shear walls are widely used for aseismic structures because of the high lateral stiffness and bearing capacity. Previous earthquake reconnaissance has shown that shear wall structures and frame-shear wall structures could effectively prevent collapse of buildings and mitigate seismic damage during severe earthquakes, and these two types of structures exhibited better performance than bare frame structures $[2,3]$. This observation has also been confirmed by the observed damages in the Wenchuan earthquake; Many frame structures suffered severe damage and even collapsed while only minor damages was observed in shear wall and shear wall-frame structures [1,4-9]. Considering their good performance, it can be expected that more and more shear wall and frame-shear wall structures will be used in the future.

\section{SEISMIC BEHAVIOR AND FAILURE MODE OF CONVENTIONAL SHEAR WALLS}

For the seismic design of conventional shear walls, there are still many issues to resolve. Under small earthquakes the

\footnotetext{
*Address correspondence to this author at the School of Civil Engineering, Yantai University, Yantai, 264005, China; Tel: +86 535 6902606;

Fax:+86 535 6902606; E-mail: housind@126.com
}

shear wall can guarantee the seismic performance, but there are some problems when it is subjected to strong earthquakes. First of all, the failure mode of shear wall is difficult to control, and shear failure is very likely to happen. Since the ductility and energy dissipation of a shear wall are poor if it fails in shear $[10,11]$, various measures have been taken to obtain flexural failure in the practice [12-15]. However, shear failure is difficult to avoid for not only short walls with aspect ratio less than 1 but also tall ones with aspect ratio greater than 2. Fig. (1) shows some typical examples of tall walls failed in shear after strong earthquakes $[6,16,17]$.

Secondly, even though the desirable flexural failure can be achieved in some designs, the damage and energy dissipation of a shear wall generally concentrated in the plastic hinge region at the bottom of the wall (see Fig. 2) [18]. The full capacity of the wall is difficult to take advantage of and the loss of axial and shearing capacity in plastic hinge region is likely to take place.

\section{DESIGN OF ADAPTIVE-SLIT SHEAR WALL}

In performance-based seismic design, the performance of shear wall is required to be able to adapt to different levels of earthquake intensities. Under small earthquakes or wind load, the wall should retain its integrity and high stiffness to meet the requirements of serviceability; under moderate earthquakes, the wall can be damaged to certain degree as long as it meets the requirements of reparability; under strong or extremely strong earthquakes, proper anti-collapse property should be guaranteed. To meet these requirements and improve the seismic performance of shear wall, a new adaptive-slit shear wall with simple construction and good performance, is introduced(see Fig. 3). Open-pored steel sheets or cold-formed thin-walled steel with web openings is placed along the axis of the reinforced concrete walls. Steel sheets 


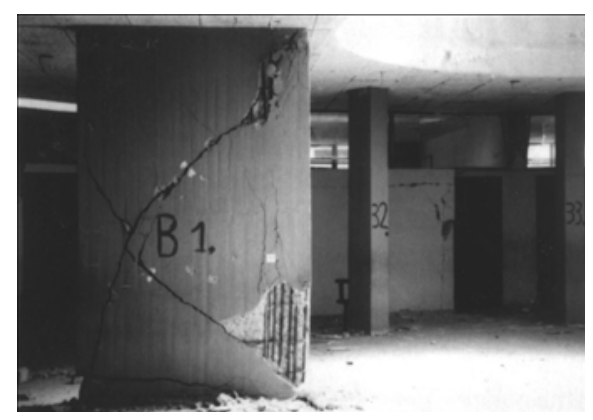

(a) A failed wall in Kalamat earthquake in 1986 [16]

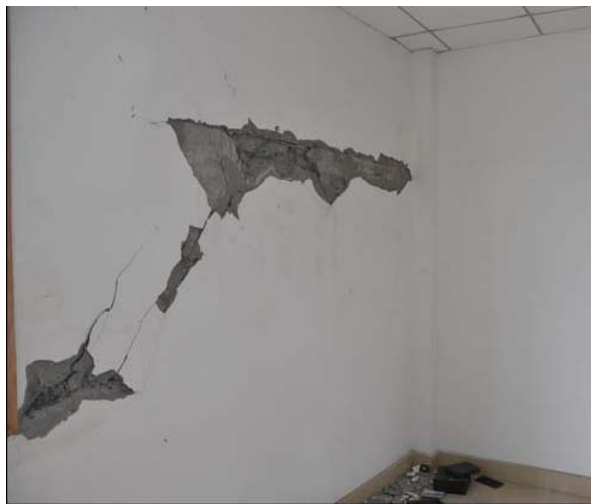

(b) A failed wall in Wenchuan earthquake in 2008 [6]

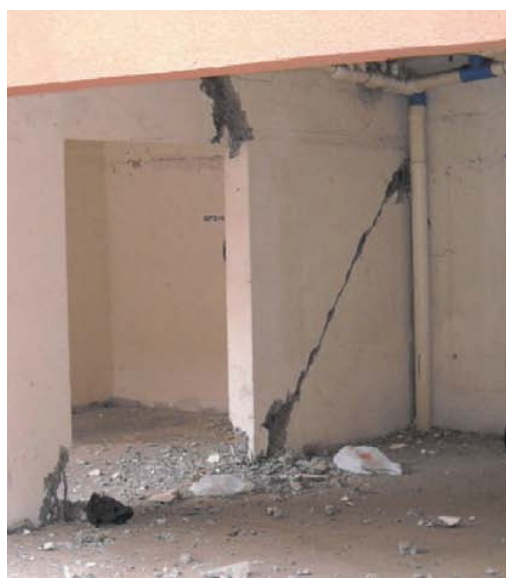

(c) A failed wall in Chile earthquake in 2010 [17]

Fig. (1, a-c). Shear failure of tall walls after strong earthquake.

can separate the concrete and replace part of the vertical reinforcement.

\section{EXPERIMENTAL STUDY ON ADAPTIVE-SLIT SHEAR WALLS}

Based on the design shown in Fig. (3), three adaptive-slit shear walls and one conventional reinforced concrete shear wall were constructed and tested [19]. The cross-section of all specimens is $1500 \mathrm{~mm} \times 170 \mathrm{~mm}$. The aspect ratios are $1.0,1.5$ and 2.0 for specimens W1, W3-L1 and W4-L2, respectively,

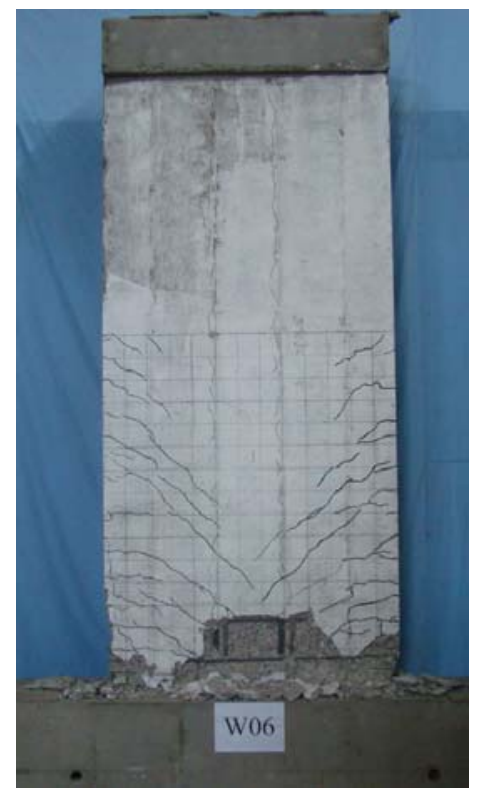

Fig. (2). Flexural failure mode of walls [19].

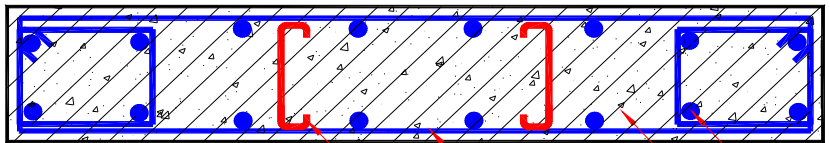

12

34

Fig. (3). Cross-section of adaptive-slit shear wall and 1.0 for the RC wall, W0. Axial force ratio is 0.15 for all specimens. Considering the "strong in flexure-weak in shear" concept, the boundary elements are reinforced with $6 \Phi 25$ HRB400 longitudinal bars. The horizontal distributed reinforcement are $\Phi 8 \mathrm{HPB} 235$ rebars at $200 \mathrm{~mm}$ spacing. The cross section of the cold-formed thin wall steel inside the shear walls is $140 \mathrm{~mm}$ in depth and, $1.1 \mathrm{~mm}$ thick. These thin wall steel functions as vertical distributed rebars, which is equivalent to two layers of $\Phi 10$ steel bars in cross section area.

Photos of Specimen W0, W1 and W3-L1 at the peak load and the failure point are shown in Fig. (4). The failure point is reached when the maximum load sustained by the specimen drops to $85 \%$ of the maximum load applied to the specimen. Specimen W0 failed at the peak load, so the two photos at peak load and failure point are the same. Top lateral force-displacement hysteresis curves and skeleton curves are shown in Figs. $(\mathbf{5}, \mathbf{6})$, respectively, where the horizontal axis is the drift ratio measured at the loading point, and the vertical axis is the shear force normalized by the nominal compressive strength of the concrete cross section.

It was found that the concrete on both ends of the diagonal cracks crushed at peak load for Specimen W0, and the width of crack increased rapidly, leading to quick decrease of both the horizontal and vertical bearing capacity and finally brittle shear failure.

In contrast to the quick failure of the reinforced concrete shear wall, the adaptive-slit shear walls failed more gradually. It is obvious that the walls exhibited two stages of performance during the loading before the final failure, namely, whole wall stage, and slit wall stage.

\section{Whole Wall Stage}

For Specimens W1 and W0, the skeleton curves before the occurrence of vertical cracks essentially match each other, and the stiffness of both walls is high. When the horizontal load was further increased, many short minor cracks along the cold-formed thin-walled steel were observed and vertical macro-cracks formed. The width of diagonal crack is very small before the peak load, and the relative deformation of 


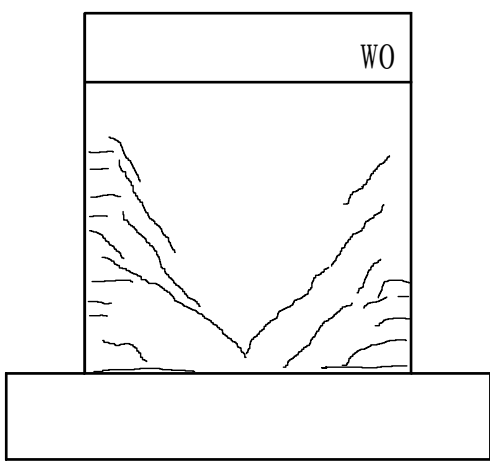

Cracks at $\pm 650 \mathrm{kN}$

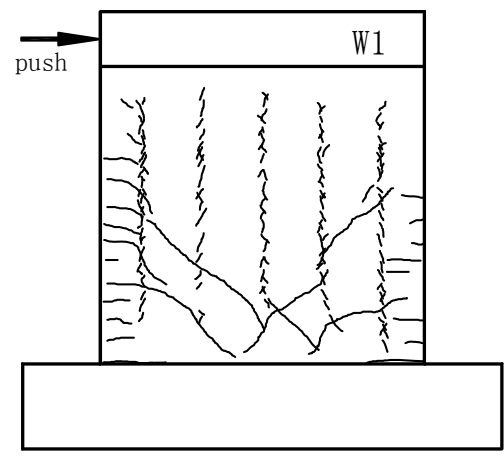

Cracks at $\pm 600 \mathrm{kN}$

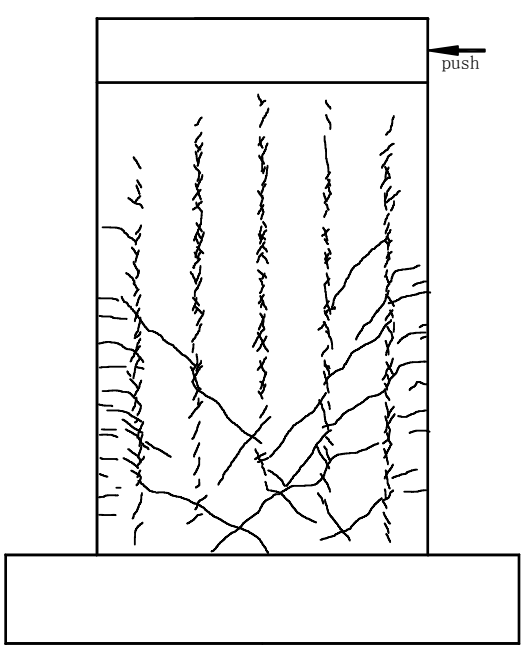

Cracks at $\pm 600 \mathrm{kN}$

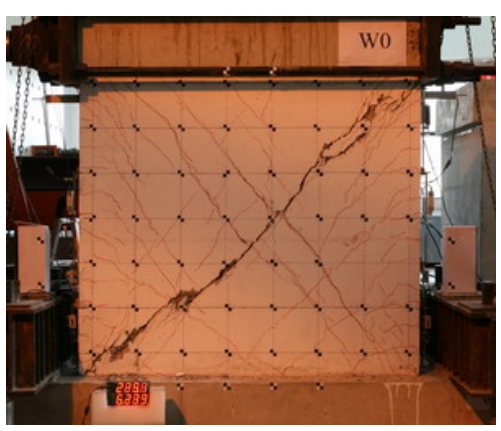

Picture at peak load

W0

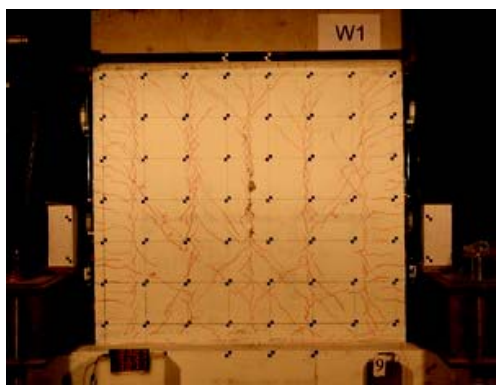

Picture at peak load

W1

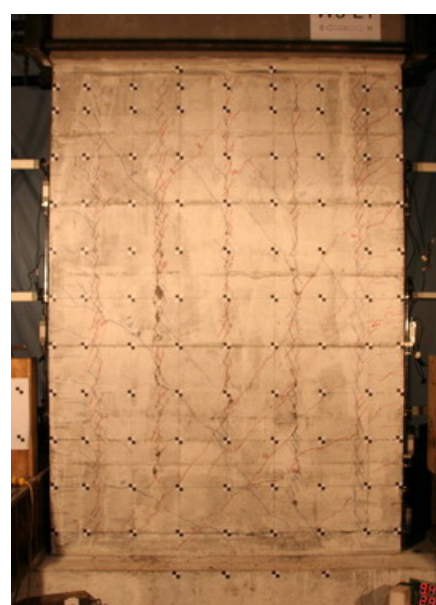

Picture at peak load

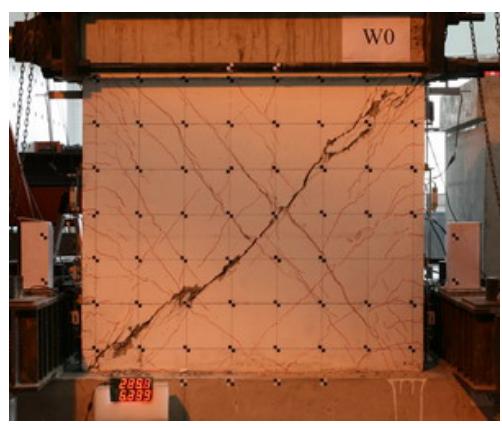

Picture at failure

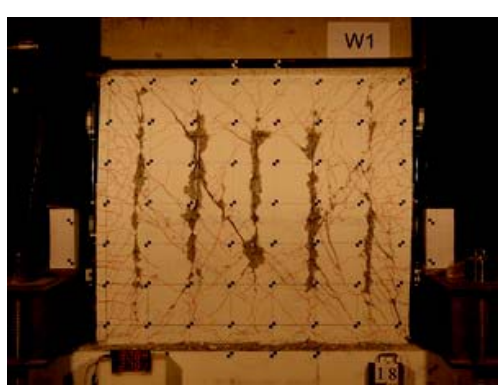

Picture at failure

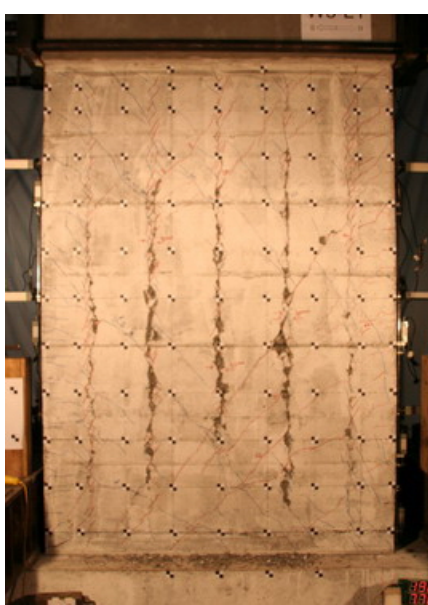

Picture at failure

W3-L1

Fig. (4). Failure process of walls.

boundary elements on both sides was also small. Therefore, the vertical macro-cracks have no effect on the overall performance of the wall and the wall works as a whole. At the same time, the vertical cracks changed the development of diagonal cracks and reduced their width. As a result, shear failure can be prevented. Also, the outermost longitudinal reinforcement of the walls did not yield at peak loads and the horizontal crack at bottom was narrow.

\section{Slitted Wall Stage}

The relative deformation of the concrete separated by the vertical cracks increased suddenly when adaptive-slit shear wall was at the peak load and then the concrete close to the vertical cracks was crushed gradually. At this stage, the adaptive-slit shear wall, which has small aspect ratio, can be considered as several 'wall columns' with large aspect ratio. The bearing capacity decreased slowly and the deformability 


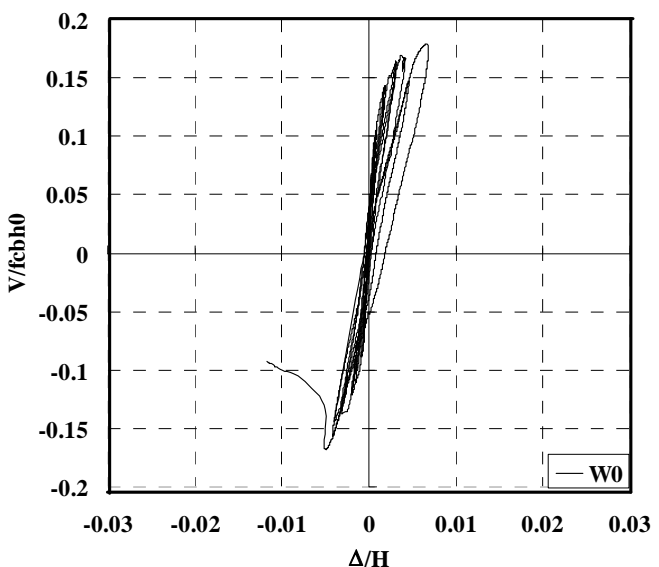

W0

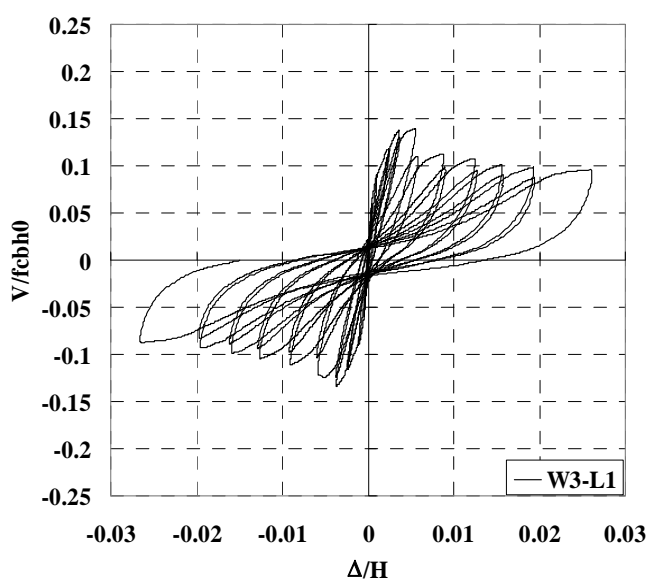

W3-L1

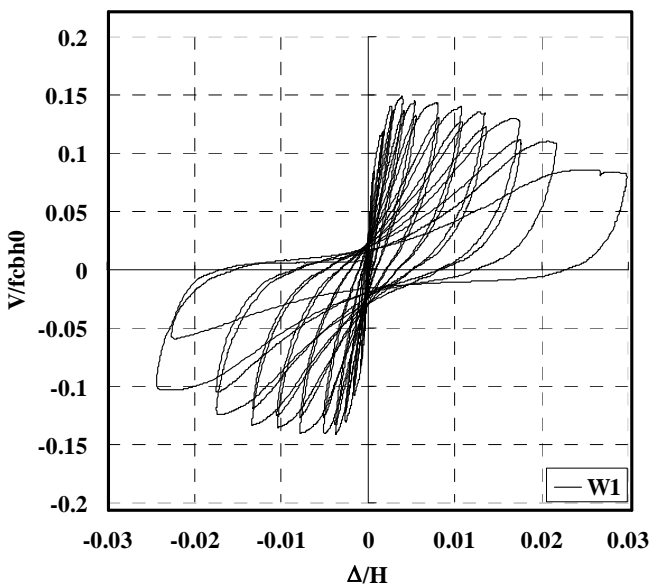

W1

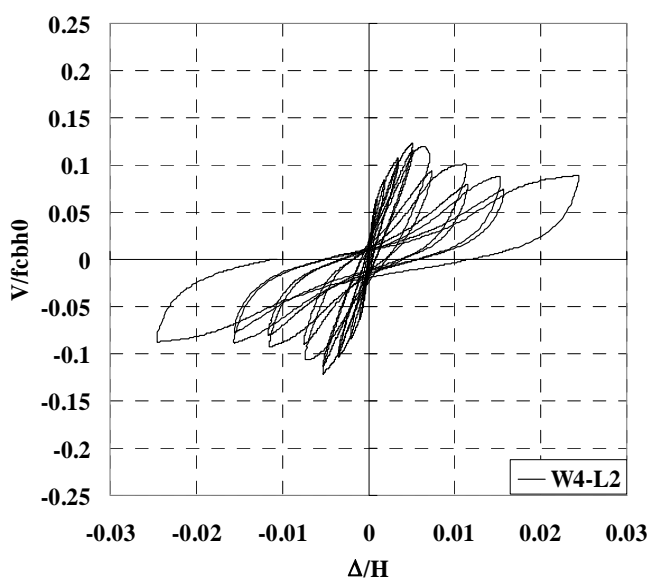

W4-L2

Fig. (5). Top lateral force-displacement hysteretic loops of walls.

was greatly improved. In this sense, the adaptive-slit shear wall exhibits good ductility. The drift ratio of W1 was 1/52 at the failure point, while the load-displacement skeleton curves of both W3-L1 and W4-L2 went almost horizontally when the

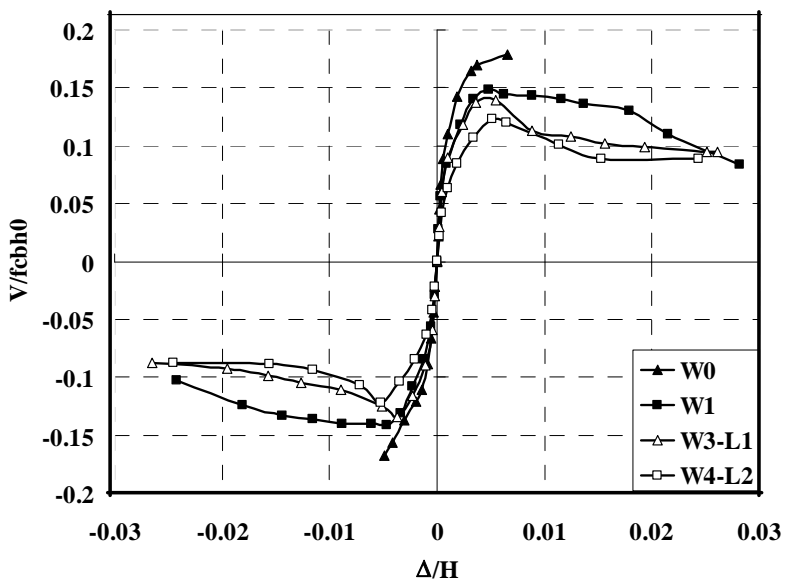

Fig. (6). Top lateral force-displacement skeleton curves of walls. bearing capacity decreased to $80 \%$ of the peak load. These results suggest that the damage and failure of the adaptive-slit shear wall are mainly concentrated in the vertical cracks, and the concrete between the vertical cracks is almost intact. Therefore, the adaptive-slit shear wall has much less loss of vertical bearing capacity under lateral loading, and thus are good for collapse prevention.

\section{ADVANTAGES OF ADAPTIVE-SLIT SHEAR WALLS}

The test results showed that the new adaptive-slit shear walls are adaptive to various seismic performance requirements for earthquakes of different intensities. Under small earthquakes, the behavior of adaptive-slit shear walls is similar to ordinary shear walls. Under moderate earthquakes, vertical cracks start near the cold-formed thin-walled steel, and gradually transform into macro-vertical cracks. Under strong earthquakes, the concrete along the vertical cracks is gradually crushed. Eventually, the walls turn into slit walls so that the ductility and deformability is significantly improved.

The superior mechanical behavior of adaptive-slit shear walls can be summarized as below: 


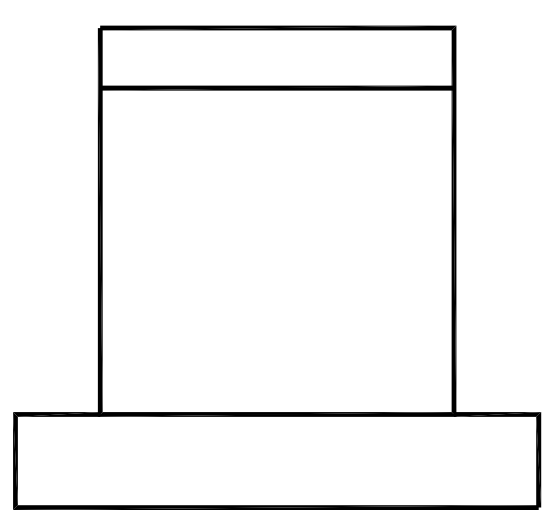

(a) Under small earthquake

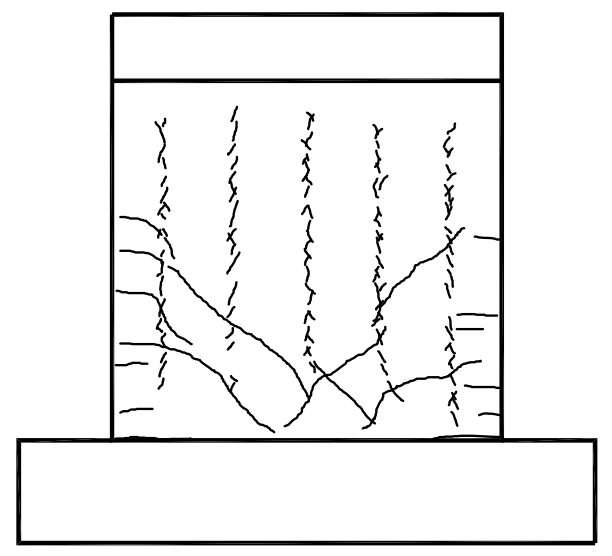

(b ) Under medium earthquake

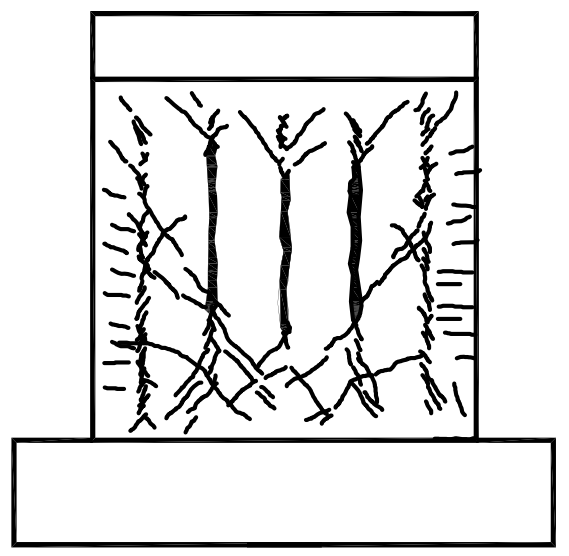

(c) Under large earthquake

Fig. (7, a-c). Condition of adaptive-slit shear wall under earthquake.

\section{Two-Stage Damage}

Two damage stages can be distinguished for adaptive-slit shear walls under seismic load, namely, the whole wall stage and the slit wall stages.

\section{Controlled Damage}

Adaptive-slit shear wall with multiple seismic fortifications can control the locations and the evolving process of the seismic damage and meet the requirements for the three seismic fortification levels prescribed in the seismic provisions in China. In adaptive-slit shear walls, because the damage first appears at the junction between cold-formed thin-walled steel and the concrete, the wall damage can be limited to predetermined positions of the wall so as to guarantee the formation of intended damage mode.

An adaptive-slit shear wall can be seen as a dual seismic resistant structural system. Wall columns and boundary elements constitute the primary structure, and the concrete in the vertical cracks and the horizontal reinforcement are the secondary structural elements. Under small earthquakes, the primary and the secondary structures are elastic and rigid to meet the serviceability requirements. As shown in Fig. (7a), which schematically demonstrates the wall condition under various seismic conditions, the wall keeps its integrity under this condition. Under moderate earthquakes, the primary structure still remains elastic. A lot of short micro vertical cracks appear in presupposed locations, which can change the development mode of the diagonal cracks and avoid the appearance of major diagonal cracks. The width of diagonal cracks can be greatly reduced compared with those in conventional shear walls. Therefore, the wall damage is relatively minor to meet the "moderate earthquake" performance requirement. The wall condition under this intensity level is schematically shown in Fig. (7b). Under strong earthquakes, the horizontal reinforcement yields, and the concrete in the vertical cracks is crushed gradually. The wall turned into slit wall and the overall seismic response can be reduced. Energy dissipation mainly relies on secondary structural elements. The main structure still has sufficient ductility and the damage is very small. Meanwhile, because the damage and failure are concentrated in vertical crack zones, vertical bearing capacity can be maintained to a large degree, so as to avoid structural collapse. So the "strong earthquake" target performance can also be satisfied. The wall condition under strong earthquake is shown in Fig. (7c). Under even larger earthquakes, the wall is still supposed to maintain large vertical bearing capacity and will not collapse.

\section{Ductile Shear Failure}

Adaptive-slit shear walls can avoid brittle shear failure and prevent the damage concentration at the bottom of the wall.

The failure of the conventional shear walls was generally concentrated in the bottom plastic hinge region, where concrete damage leads to reduction of cross-section area, loss of bearing capacity and stiffness, and decrease in the shear capacity and anti-slip capacity. Shear strength is mainly dependent on the reinforcement $[20,21]$ and some necessary measures have to be taken to reduce the wall slip deformation in conventional shear walls [14]. In order to improve the ductility and anti-collapse ability, the construction of boundary elements and the limit of axial force ratio are considered in some relevant specifications [22], which may increase the amount of material used. Even with these design principles, shear failure still frequently occurs in practice. In addition, cantilever shear wall structure is statically determinate. It becomes unstable as long as one plastic hinge occurs. Coupled walls are commonly used to improve the performance. As a result, the structure changes into a statically indeterminate system; however, this strategy causes a new dilemma. The coupling beam is a shear sensitive member. Although the coupled shear wall is designed by "weak beam-strong wall" principle to dissipate earthquake energy, it is difficult to achieve the design goal in practice, e.g. coupling beams generally fail in shear, as observed in the Wenchuan earthquake [6]. Therefore, it is theoretically feasible to design conventional shear walls by "strong shear-weak bend" and "strong wall-weak beam" principles, but there are still some difficulties in the practice. Adaptive-slit shear wall can solve the above issues in conventional shear walls. Firstly, adaptive-slit shear walls have good ductility and deformation capacity, because they can avoid brittle shear failure without considering the "strong shear-weak bending" design principle. 
The walls can even be designed by "strong bend-weak shear " principle to achieve better performance. The stiffness of the wall can be significantly enhanced by using more longitudinal reinforcement at the serviceability level. When failure occurs, development of horizontal and diagonal cracks is postponed. Because there is no concentrated plastic hinge regions in the wall, the loss of vertical bearing capacity and sliding strength is much reduced. For cantilever adaptive-slit shear wall, since failure is concentrated in vertical cracks, the wall can be statically indeterminate automatically after it turns into a slit wall.

\section{High Material Efficiency}

In conventional shear walls, only the vertical reinforcement and concrete within the plastic hinge region can work efficiently. For adaptive-slit shear walls, horizontal reinforcement yields under peak load and longitudinal reinforcement gradually yields after peak load. It means when the wall is destroyed, most reinforcement yields. Also, the concrete in an adaptive-slit shear wall fails in a large and distributed area. Therefore, the capacity of the materials used to construct the wall could be better utilized.

Shear walls are the skeleton to withstand gravity loads in a structural system. At the same time, they are the main members to determine the energy absorption capacity of a building during earthquakes. Because the damage and energy dissipation in adaptive-slit shear walls are obtained by the development of vertical cracks, which are distributed in a large area, the adverse effects of concentrated energy dissipation at the wall bottom, which is often observed in conventional shear walls, can be avoided. Therefore, the design of adaptive-slit shear walls is effective to ensure the bearing capacity and anti-collapse ability of building structures. At the same time, this type of structure is relative easy to be repaired and strengthened after earthquakes because the damage is not concentrated at the bottom of the walls [23].

\section{CONCLUSION}

Previous earthquake reconnaissance shows that wall structures and frame-wall structures have better seismic performance than bare frame structures, which have been more and more widely used. However, for conventional shear walls, the failure mode of ordinary wall piers is difficult to control and the shear failure is easy to happen. Even though the desired flexural failure mode could be obtained, damage and energy dissipation are generally concentrated in the plastic hinge regions at the bottom of the wall. Therefore, loss of vertical bearing capacity and shear capacity occurs quickly and easily under strong earthquakes.

A new adaptive-slit shear wall with excellent seismic performance and simple construction, which can solve many issues for conventional shear wall, is presented herein. Studies show that based on the mechanical characteristics of adaptive-slit shear walls, this new design could be adaptive to the seismic performance requirements for building structures under earthquakes of various intensities. The failure process of this new structure is progressive and can be divided into two stages, i.e., the whole wall stage and the slit wall stage. For adaptive-slit shear walls with multiple seismic fortifica- tions, the damage process can be better controlled. More importantly, ductile failure can be achieved for the design of adaptive-slit shear walls and brittle shear failure can be avoided, which happens in ordinary shear walls, especially in squat walls.

\section{CONFLICT OF INTEREST}

The authors confirm that this article content has no conflicts of interest.

\section{ACKNOWLEDGEMENTS}

The authors are grateful to the support of National Natural Science Foundation of China (Grant No. 51078321 and 51378450).

\section{REFERENCES}

[1] L. Ye, Z. Qu, X. Lu, and F. Peng, "Collapse prevention of building structures: a lesson from the Wenchuan earthquake," Journal of Building Structures, vol. 29, pp. 42-50, August 2008.

[2] M. Fintel, "Ductile shear walls in earthquake resistant multistory buildings", ACI J, vol. 53, pp. 117-126, January 1977.

[3] M. Fintel, "Performance of buildings with shear walls in earthquakes of the last thirty years," PCI J, vol. 40, pp. 62-80, May-June 1995.

[4] Y. Mo, J. Jin, Y. Du, and B. Cao, "A probe in structural form selection for buildings in high-intensity earthquake region -reflection on issues of structural form selection in survey on damages of Wenchuan earthquake on may 12th to architectural structure of buildings in Longnan area," Earthquake Resistant Engineering and Retrofitting, vol. 30, pp. 50-55, August 2008.

[5] B. Yin, S. Huang, Y. Xue, and X. Ge, "Seismic damage investigation and thinking on the damage buildings of frame-shear wall structure in Wenchuan 5.12 earthquake," Earthquake Resistant Engineering and Retrofitting, vol. 30, pp. 37-40, August 2008.

[6] Tsinghua University, Southwest Jiaotong University, Chongqing University., Buidling seismic damage in Wenchuan Earthquake and corresponding design strategy, China Building Industry Press: Beijing, 2009.

[7] H. Li, S. Xiao, and L. Hu, "Damage investigation and analysis of engineering structures in the Wenchuan earthquake," Journal of Building Structures, vol. 29, pp. 10-19, August 2008.

[8] Y. Wang, "Lessons learnt from building damages in the Wenchuan earthquake-seismic concept design of buildings," Journal of Building Structures, vol. 29, pp. 20-25, August 2008.

[9] L. Han, D. Jin, and Y. Mo, "Preliminary analysis on the seismic damage to the high-rise reinforced concrete frame structure - thoughts about the seismic damage of the high-rise reinforced concrete frame structure in Dujiangyan," Earthquake Resistant Engineering and Retrofitting, vol. 30, pp. 41-44, August 2008.

[10] R. G. Oesterle, J. D. Aristizabal-Ochoa, K. N. Shiu, and W. G. Corley, "Web crushing of reinforced concrete structural walls," ACI Journal Proceedings, vol. 81, pp. 231-242, May-June 1984.

[11] K. Pilakoutas, and A. Elnashai, "Cyclic behavior of reinforced concrete cantilever walls, part I-experimental results," ACI Structural Journal, vol. 92, pp. 271-281,May-June,1995.

[12] T. Paulay, M. J. N. Priestley, and A. J. Synge, "Ductility in earthquake squat shear walls," ACI Journal, vol. 79, pp. 257-269, July 1982 .

[13] GB50011 - 2010, Code for seismic design of buildings, 2010.

[14] European Committee of Standardization, "Eurocode 8: Design of structures for earthquake resistance-part 1: General rules, seismic actions and rules for buildings," Brussels, Belgium, 2003.

[15] ACI Committee, "Building code requirements for structural concrete(ACI318-08) and commentary(ACI318R-08) American Concrete Institute," Farmington Hills, Michigan, 2008.

[16] M. S. Lopes, "Experimental shear-dominated response of RC walls Part I: Objectives, methodology and results," Engineering Structures, vol. 23, pp. 229-239, March 2001. 
[17] F. Rojas, F. Naeim, M. Lew, and L. D. Carpenter, "Performance of tall buildings in Concepción during the 27 February 2010 moment magnitude 8.8 offshore Maule, Chile earthquake," The Structural Design of Tall and Special Buildings, vol.20, pp. 37-64, February 2011.

[18] Q. Huang, "Study on Seismic Performance of Lightweight-steel Framework SRC Shear Walls," M.S. thesis, Tsinghua University, Beijing, China, 2009.

[19] M. Chu, "Seismic behavior of cold-formed thin-walled steel reinforced concrete shear walls," Ph.D. dissertation, Tsinghua University, Beijing, China, 2010.
[20] Canadian Standards Association, "CSA Standard CAN3-A23. 3-04. Design of concrete structures for buildings with explanatory notes," Rexdale, Canada, 2004.

[21] Park R, and Paulay T, Reinforced Concrete Structures, John Wiley \& Sons, New York 1975.

[22] JGJ 3-2010, Technical specification for concrete structures of tall building, 2010 .

[23] Xilin Lv, and Xiaohan Wu, "Shaking table test and numerical analysis for shear wall with a new type seismic energy dissipation system," Earthquake Engineering and Engineering Vibration, vol. 16, pp. 70-77, January 1996.

Received: April 08, 2013

Revised: August 06, 2013

Accepted: August 07, 2013

(C) Sun et al.; Licensee Bentham Open.

This is an open access article licensed under the terms of the Creative Commons Attribution Non-Commercial License (http://creativecommons.org/licenses/ by-nc/3.0/) which permits unrestricted, non-commercial use, distribution and reproduction in any medium, provided the work is properly cited. 